\title{
Effect of Ankle Joint Mobilization with Movement on Range of Motion, Balance and Gait Function in Chronic Stroke Survivors: Systematic Review of Randomized Controlled Trials
}

\author{
Abayneh Alamer (iD) \\ Haimanot Melese (D) \\ Kefale Getie (ID) \\ Sisay Deme $\mathbb{1 D}^{\prime}$ \\ Molla Tsega $\mathbb{( D}^{2}$ \\ Sileshi Ayhualem (1D) ${ }^{3}$ \\ Gebremeskel Birhanie ${ }^{4}$ \\ Yohannes Abich (D) ${ }^{5}$ \\ Asmare Yitayeh Gelaw $\mathbb{D}^{5}$ \\ 'Department of Physiotherapy, School of \\ Medicine, College of Health Sciences and \\ Ayder Comprehensive Specialized \\ Hospital, Mekelle University, Mekelle, \\ Ethiopia; ${ }^{2}$ Department of Internal \\ Medicine, School of Medicine, College of \\ Health Sciences and Ayder \\ Comprehensive Specialized Hospital, \\ Mekelle University, Mekelle, Ethiopia; \\ ${ }^{3}$ Department of Anatomy, College of \\ Medicine and Health Sciences, University \\ of Gondar, Gondar, Ethiopia; \\ ${ }^{4}$ Department of Physiotherapy, School of \\ Medicine, College of Health Sciences, \\ TibebeGhion Comprehensive Specialized \\ Hospital, Bahir Dar University, Bahir Dar, \\ Ethiopia; ${ }^{5}$ Department of Physiotherapy, \\ College of Medicine and Health Sciences, \\ University of Gondar, Gondar, Ethiopia
}

Correspondence: Abayneh Alamer

Tel +25I 922276256

Fax +25I 34441668I/9I

Email abayphysio@gmail.com
Background: Ankle joint mobilization with movement has been speculated to be an important intervention for enhancing range of motion, balance, and gait functions in chronic stroke survivors. Nonetheless, there is a scarcity of recent conclusive evidence that evaluates its efficacy in chronic stroke patients. The purpose of this review was to synthesize existing evidence on the efficacy of mobilization with movement therapy on range of motion, balance, and gait performance in subjects after stroke.

Methods: A comprehensive systematic search of literature was performed using the following databases: PubMed/Medline, CINAHL, AMED, PEDro, Cochrane Library, and Scopus. Physiotherapy Evidence Database (PEDro) scale was used to evaluate the methodological quality of included trials. The primary outcome measures of this review were dorsiflexion range of motion (DF-ROM), and Berg balance scale (BBS). This review was reported in accordance with PRISMA statement guidelines. Due to variations in relevant trials, meta-analysis was not carried out.

Results and Conclusions: Seven randomized controlled trials with a total of 224 subjects were analyzed. Evidence of overall quality was graded from moderate to high. This review found that mobilization with movement therapy could be an alternative rehabilitative intervention for subjects with chronic stroke to increase range of motion, balance, and gait ability. However, the evidence remains preliminary due to the small number of participants. Largescale RCTs in the future are warranted to investigate the efficacy of mobilization with movement in subgroups of chronic stroke subjects.

Keywords: chronic stroke, Mulligan's mobilization with movement, range of motion, gait, balance, systematic review

\section{Introduction}

Stroke can lead to spasticity and restricted ankle range of motion (ROM), which may be severely disabling. ${ }^{1,2}$ In chronic stroke patients, limited ankle ROM is a common health problem. ${ }^{3,4}$ Disabilities and functional restriction of patients can be worsened by the interaction of various factors like; immobility, structural adaptations, and spasticity which affect ankle ROM. ${ }^{5}$ Consequently, these patients have decreased weight-shifting stability, and diminished balance ability, which could contribute to decreased gait performance and an increased risk of falling. ${ }^{6}$ Decreased balance and gait performance have a significant impact on their ability to perform various everyday activities. $^{1,7}$ 
Nowadays various interventions, including calf muscle stretching, muscle strength training, functional electrical stimulation training, proprioceptive control training, and ankle mobilization with movement (MWM) have been used to enhance ankle dorsiflexion passive range of motion (DFPROM), gait function, and balance ability in individuals with stroke., ${ }^{5,-11}$

MWM was proposed by Mulligan as a joint mobilization approach. ${ }^{12}$ A posterior anterior tibial glide is applied over a set talus while the patient deliberately transitions into a dorsiflexed posture while standing to facilitate DF-ROM. ${ }^{13}$ Besides, using a strap can provide ankle self-mobilization practice for the dorsal glide of the talus during closed-chain ankle dorsiflexion exercises, and the strap can provide talus stabilization by holding it during the lunge exercise. ${ }^{14} \mathrm{MWM}$ is substantially paramount to decrease talar positional fault and restore an accessory movement (posterior talar glide) on ankle joint. ${ }^{13,14}$ Thus, restoring of posterior talar glide leads to improved ankle dorsiflexion ROM.

Previous studies showed that MWM improved ankle DFROM, gait function, and balance among people with chronic stroke. ${ }^{15,16}$ Studies done by Park et al, reported that selfankle MWM with a $10^{\circ}$ inclined board (MWM10 ${ }^{\circ}$ ) combined with conventional physiotherapy resulted in improved motor functions of subjects with chronic stroke. ${ }^{16}$ However, there is a lack of comprehensive evidence about the efficacy of ankle joint MWMs in ROM, balance, and gait function in people with chronic stroke. Given these drawbacks, its adequacy in the treatment of ankle range of motion, balance, and gait function in chronic stroke patients remains unclear. As a result, the aim of this review was to synthesize the efficacy of ankle joint MWMs on ROM, balance, and gait function in chronic stroke survivors.

\section{Methods}

\section{Design}

This review was done and reported in accordance with Preferred Reporting Items for Systematic Reviews and Meta-Analyses (PRISMA) guidelines. ${ }^{17}$

\section{Search Strategy}

An electronic search was conducted on the following databases; PubMed/MEDLINE, CINAHL, AMED, PEDro, EMBASE, Cochrane, and Scopus to identify all eligible randomized controlled trials. The terms "stroke/ cerebrovascular injury", "Movement with Mobilization", "ROM", "Balance", and "Gait function" were used as keywords. As title headings switched between databases, different key word combinations were used as follows: "stroke/cerebrovascular accident", AND "Mobilization with Movement"/“Mulligan's Mobilization with Movement", AND "balance/stability", AND "walking/ gait/mobility", AND "Range of motions" AND "randomized controlled trial". The retrieval of the included studies was carried out between October 2015 and May 2021. Manual searches were also performed from the reference list of included documents.

\section{Eligibility Criteria}

Each study's eligibility was evaluated using the PICO (Population/problem(s), intervention(s), comparison(s), outcome(s)) framework. PICO refers to a well-focused scientific study issue in terms of a particular patient issue that helps the searcher find scientifically applicable data in the literature. ${ }^{18}$ This approach helps the clinician in articulating the therapeutic issue that is most relevant to the patient and supports the discovery process by defining the core principles for an appropriate search strategy. ${ }^{19,20}$

\section{Inclusion Criteria}

Studies searched were considered qualified in case they met the subsequent standards 1) Population: participants with all types of chronic stroke ( $\geq 3$ months duration); 2) Intervention: experimental groups received MWMs; 3) Comparison/s: control group received conventional physiotherapy, and 4) Outcomes; ROM, balance, and gait function. Only full-text articles published in English language in peer reviewed journals were considered. This review considered adults with hemiplegia/hemiparesis who were at chronic/late-stage of stroke. RCTs that compared the efficacy of MWMs and/or conventional physiotherapy (CPT) versus CPT (Weight bearing with placebo MWM, ROM exercise, weight bearing exercise, calf muscle stretching, gait training/ walking training and static muscle stretching) were included.

\section{Exclusion Criteria}

Observational studies, conference abstracts, published articles in non-English language, and quasi experimental studies were excluded from this study.

\section{Study Selection}

Two reviewers (A.A. and K.G.) extracted journal articles from the outlined lists based on title/abstract, using predetermined eligibility criteria. The studies were collected, and retrieved in-depth through methodological quality and 
data extraction tools. The third reviewer (H.M) was on hand to solve any disagreement between the two reviewers.

\section{Risk of Bias in Individual Studies}

Three authors assessed the accuracy of specific trials using the PEDro (Physiotherapy Evidence Database) Scale, which consists of 11 items, with the first item (article external validity). ${ }^{21,22}$ The PEDro scale was used to assess the methodological quality of trials based on key parameters such as; concealed assignment, intention-to-treat analysis, and appropriate follow-up. These features make the PEDro scale a useful tool for assessing the methodological quality of RCTs. This review considered trials with a score of 5 to 7 as moderate quality, and a rating of $\geq 8$ as a high-quality study (Table 2).

\section{Data Extraction}

Data extraction was done based on the pre-designed data retrieval template. Two reviewers (A.A \& K.G) extracted the data independently and the third author checked the extracted data. Disagreements had been settled through discourse with the third author. The following information was extracted from each RCT: author's name and year of publication, stroke (severity, type, and duration), number of participants in experimental and control groups, types of treatments in both experimental and control groups, mean follow-up period, participants' mean age, and treatment results (baseline, follow-up, and post-treatment). The effect of interventions on each result, mean and standard deviations of outcome measures at baseline, after treatment, and during follow-up, were extracted and synthesized.

\section{Results}

\section{Study Selection}

A total of 900 articles were identified by the search strategy. After removing duplicates, 600 remained. After title and abstract screening of studies; 561 studies were excluded. After full content screening, out of 32 articles, 7 RCTs were included in this review (Figure 1).
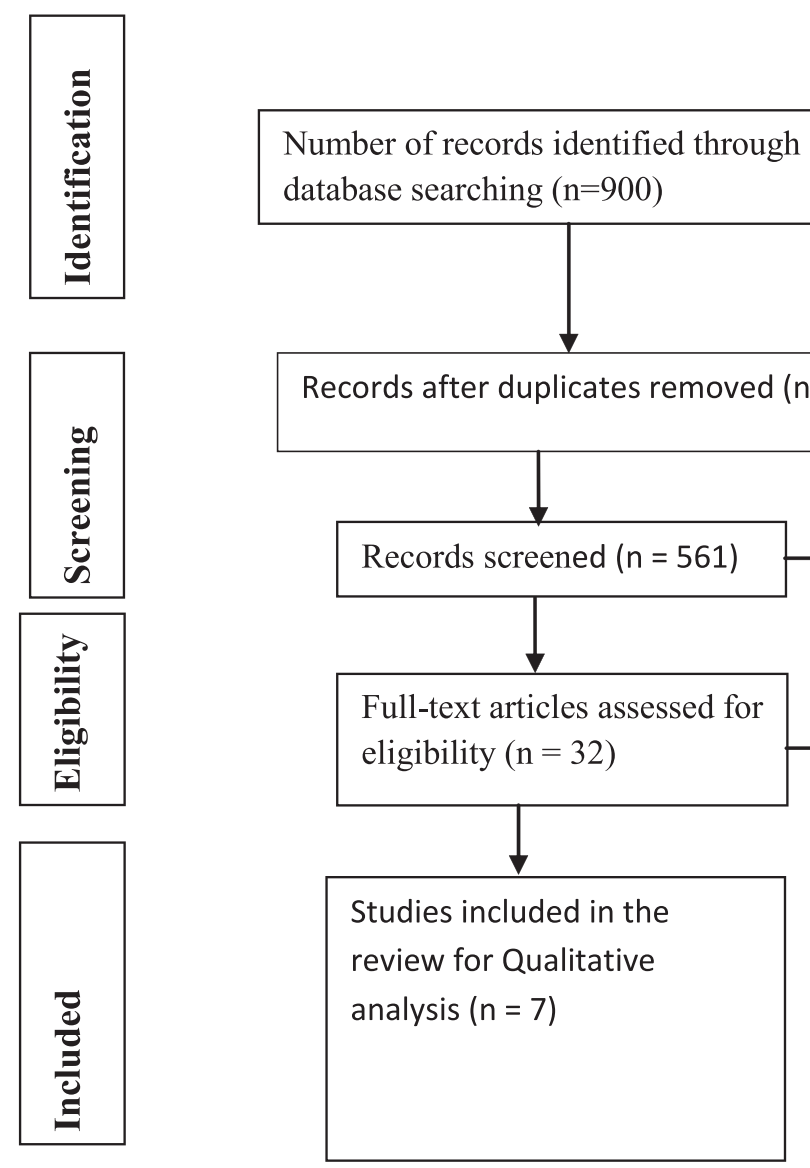

Additional records identified through other sources $(n=0)$

Records excluded $(n=529)$

\begin{tabular}{|l|l|}
\hline & $\begin{array}{l}\text { Full-text articles excluded, with reasons, } \\
\text {-Abstracts }(\mathrm{n}=4) \\
\text {-Non English language }(\mathrm{n}=6) \\
\text { - Not RCTs }(\mathrm{n}=5) \\
\text { - Did not use MWMs }(\mathrm{n}=6) \\
\text { - No relevant outcome data were reported } \\
(\mathrm{n}=4) \\
\text { Total }(\mathrm{n}=25)\end{array}$
\end{tabular}

Figure I PRISMA flow diagram.

Notes: Adapted from Liberati A, Altman D, Tetzlaff J, et al. The PRISMA statement for reporting systematic reviews and meta-analyses of studies that evaluate health care interventions: explanation and elaboration. Journal of Clinical Epidemiology. 2009;62(10)el-e34. Creative Commons. 


\section{Study Characteristics}

Detailed descriptions of characteristics and results of the outcomes for the included trials are presented in Table 1. A total of 7 trials with 224 participants were synthesized. All seven trials examined the effects of mobilization with movement on ROM and gait function. Out of the included studies, six of them investigated the adequacy of mobilization with movement in balance ability of individuals with chronic stroke. ${ }^{15,16,23-27}$ The synthesized characteristics and outline of the results of the included trials based on PICO standard are described in the following sections.

\section{Participants}

The majority of trials were from rehabilitation center members who had suffered stroke. The participants' mean age ranged from 41.58 (10.5) to 64.1 (9.7) years. ${ }^{16,23}$ The mean duration after stroke diagnosis ranged from 8.6 (1.5) to 62.7 (42) months. ${ }^{24,25}$ The majority of included studies enrolled more participants who had suffered a hemorrhagic injury.

\section{Interventions}

Studies comparing the effects of MWMs and/or CPT, and comparisons/control group: received CPT and/or placebo MWMs were considered. The treatment duration ranged from 20 to 30 minutes per session, 3 to 5 times per week for 4 to 5 week period. ${ }^{15,25}$

\section{Outcome Measures}

Data were extracted for the following outcomes: ROM, balance, and gait function. DF-ROM and BBS were primary outcome measures of this review. Five studies ${ }^{16,24-27}$ used DF-ROM for ankle range of motion assessment. Six trials ${ }^{16,23-27}$ used GAITRite system for gait spatial parameters. Two trials ${ }^{16,26}$ utilized static balance score to rate balance capability and only one tria ${ }^{15}$ used Time Up and Go Test for mobility/gait assessment. Only three trials $^{16,24,25}$ used Korean version of the Modified Barthel Index (k-MBI) to assess the daily functional status of the participants (Table 1).

\section{Risk of Bias Within Studies}

The possibility of predisposition within each trial and conclusion of all items for the enlisted studies appear in Table 1. Out of the included studies, PEDro rating ranged from $5^{25}$ to $7^{15}$ with a mean score of 6 . All participants were assigned randomly, and all trials were evaluated for baseline comparability, between-group comparisons, and acceptable outcomes. As it were, six trials used concealed allocation, ${ }^{15,16,23,25-27}$ and two trials did not blind the assessor. ${ }^{24,25}$ Only four trials assessed intention to treat analysis ${ }^{15,23,26,27}$ and all included studies did not blind the therapist and their members. ${ }^{15,16,23-27}$ The lower scoring trials were basically checked for blinding of members, deliberate/intention to treat analysis, and blinding of therapist.

\section{Effects of MWMs on ROM}

Detailed data on ankle ROM from each article have been summarized and presented in Table 1. Out of the included studies; five trials with individuals reported the furnished remedy effect on ankle dorsiflexion range of motion. All of these studies ( $\mathrm{n}=170$ subjects) proved that ankle range of motion of stroke survivors were significantly improved in MWMs groups compared to control groups. ${ }^{16,24,25,27}$

\section{Effects of MWMs on Balance}

Seven studies, with individuals, provided published treatment effect on balance. ${ }^{15,16,23-27}$ Out of seven studies, six of them ( $\mathrm{n}=198$ subjects) mentioned that balance ability of stroke patients was significantly enhanced in MWMs groups relative to the control groups in all outcome measures (BBS, TUG). ${ }^{15,16,23,25-27}$ Conversely, one study ( $\mathrm{n}=26$ subjects) found that mobilization with movement had no effect on balance capacity as compared to control groups. ${ }^{24}$ The static balance scale tests showed a significant change in the experimental intervention category.

\section{Effects of MWMs on Gait Function}

All of the included studies, with a total of 224 participants had a post-treatment effect on gait spatial parameters. ${ }^{15,16,23-27}$ All of the included trials $(n=224$ subjects) indicated that MWMs had a positive impact on gait function as compared to control groups. ${ }^{15,16,23,24,26}$ Despite this fact; one study ( $\mathrm{n}=30$ subjects) showed that only gait velocity was substantially enhanced among other gait spatial parameters. ${ }^{25}$

\section{Discussion}

The purpose of this systematic review was to summarize the effect of ankle mobilization with movement therapy on range of motion, balance, and gait function in chronic stroke survivors. To the best of the authors' knowledge, there has been no systematic review that has examined the efficacy of ankle mobilization with movement 
Table I Summary of Included Randomized Controlled Trials

\begin{tabular}{|c|c|c|c|c|}
\hline Authors & Participants & Intervention & $\begin{array}{l}\text { Outcome } \\
\text { Measures }\end{array}$ & Results \\
\hline $\begin{array}{l}\text { Chang-Man } \\
\text { An, and } \\
\text { Shin-Jo, } \\
(2017)^{24}\end{array}$ & $\begin{array}{l}26 \text { chronic stroke } \\
\text { patients: } \\
E G(n=13) \text { and } \\
C G(n=\mid 3) \\
\text { Mean age(years): } \\
E G=48.5(I I .3) \text {, } \\
C G=48.3(I 0.1) \\
\text { Duration since } \\
\text { stoke (months): } \\
E G=6 I(36.6) \text {, } \\
C G=60.7(38.1)\end{array}$ & $\begin{array}{l}E G=\text { MWM } 6 \text { sets of } 10 \text { repetitions were } \\
\text { applied, with a I-minute break } 3 \text { times a week } \\
\text { for } 5 \text { weeks plus CPT. } \\
C G=\text { conventional Physiotherapy (passive and } \\
\text { active ROM exercise, weight bearing exercise) } \\
30 \text { minutes per session } 3 \text { times a week for } 5 \\
\text { weeks. }\end{array}$ & $\begin{array}{l}\text { DF-PROM } \\
\text { K-MBI } \\
\text { MAS } \\
\text { GAIT } \\
\text { Ritesystem } \\
\text { Biodex } \\
\text { Balance } \\
\text { System }\end{array}$ & $\begin{array}{l}\text { DF-PROM was significantly increased in the } \\
\left.\text { MWM group (mean changes, } 6.67^{\circ}\right) \text { than in } \\
\left.\text { the control group (mean changes, } 0.75^{\circ}\right)(P< \\
0.0 I \text { ). Plantar flexor strength significantly } \\
\text { increased in the MWM group compared with } \\
\text { the control group ( } P<0.05 \text { ). LOS scores } \\
\text { were not significantly improved for MWM } \\
\text { group compared to the control ( } P>0.05 \text { ). } \\
\text { The paretic direction LOS was significantly } \\
\text { increased within the MWM group }(P<0.01 \text { ). }\end{array}$ \\
\hline $\begin{array}{l}\text { Sang Lim } \\
\text { Kim, and } \\
\text { ByoungHee } \\
\text { Lee } \\
(2018)^{15}\end{array}$ & $\begin{array}{l}30 \text { chronic stroke } \\
\text { patients: } \\
E G(n=15), C G \\
(n=15) \\
\text { Mean age (years): } \\
E G= \\
, 49.5(9.3), C G, 50 \\
(10.4) \\
\text { Duration since } \\
\text { stroke(months): } \\
E G=, 60(27.5) \\
C G=58.5(12.5)\end{array}$ & $\begin{array}{l}\text { EG= WMWM was treated with } 10 \text { glides of } 5 \\
\text { sets a day, } 5 \text { times a week during } 4 \text { weeks. } \\
C G=\text { Weight bearing with placebo MWM or } \\
10 \text { lunges of } 5 \text { sets a day, } 5 \text { times a week } \\
\text { during } 4 \text { weeks. }\end{array}$ & $\begin{array}{l}\text { WBLT } \\
\text { TUG } \\
\text { DGI }\end{array}$ & $\begin{array}{l}\text { The WBMWM group showed significantly } \\
\text { greater improvement than control group in } \\
\text { WBLT, static balance measures, TUG, and } \\
\text { DGI }(P<0.05) \text {. }\end{array}$ \\
\hline $\begin{array}{l}\text { Donghwan } \\
\text { Park et al } \\
(2019)^{26}\end{array}$ & $\begin{array}{l}20 \text { chronic stroke } \\
\text { participants: } E G(n \\
=10), C G(n=10) \\
\text { Mean age(years): } \\
E G=57.4(6.9), \\
C G=60.3(6.17) \\
\text { Duration since } \\
\text { stroke(months): } \\
E G=8.6(1.5), \\
C G=8.2(1.69)\end{array}$ & $\begin{array}{l}E G=M W M \text { performed } 3 \text { sets with } 10 \\
\text { repetitions per day } 3 \times \text { per week for } 4 \text { weeks. } \\
C G=S M S \text { were performed three times per } \\
\text { week for } 4 \text { weeks. } \\
\text { Both groups underwent CPT for } 30 \text { min } \\
\text { per session. }\end{array}$ & $\begin{array}{l}\text { DF-PROM } \\
\text { SBA } \\
\text { BBS } \\
\text { Gait } \\
\text { parameters }\end{array}$ & $\begin{array}{l}\text { After } 4 \text { weeks of intervention, the MWM } \\
\text { group showed significant improvement in } \\
\text { SBA, BBS, and cadence outcome measures } \\
\text { compared to the SMS group }(p<0.05) \\
\text { Furthermore, the MWM group showed } \\
\text { significant improvement in all outcome } \\
\text { measures compared with baseline }(p<0.05) \text {. }\end{array}$ \\
\hline $\begin{array}{l}\text { Donghwan } \\
\text { Park et al } \\
(2020)^{27}\end{array}$ & $\begin{array}{l}38 \text { chronic stroke } \\
\text { participants: } E G \\
(n=19) \text { and } C G \\
(n=19) \\
\text { Mean age (years): } \\
E G=62.5(6.6), \\
C G=60.5(4.5) \\
\text { Duration since } \\
\text { stroke(months): } \\
E G=10.2(2.8), \\
C G=10.4(2.8)\end{array}$ & $\begin{array}{l}E G=S-M W M \text { were performed } 3 \text { times per } \\
\text { week for } 4 \text { weeks } \\
C G=C M S \text { were performed } 3 \text { times per week } \\
\text { for } 4 \text { weeks. } \\
\text { All patients received standard physiotherapy } \\
\text { for } 30 \text { minutes per session. }\end{array}$ & $\begin{array}{l}\text { DF-PROM } \\
\text { GAITRite } \\
\text { system and } \\
\text { Biodex } \\
\text { Balance } \\
\text { System }\end{array}$ & $\begin{array}{l}\text { After completing the study interventions, gait } \\
\text { speed, cadence, affected-side stride length, } \\
\text { and } \\
\text { unaffected-side stride length were } \\
\text { significantly } \\
\text { improved by } 73.4 \%, 78.7 \%, 97.9 \% \text {, and } \\
109.9 \% \text {, } \\
\text { respectively, in the S-MWM group as } \\
\text { compared } \\
\text { with the CMS group. Compared with the } \\
\text { CMS group, ankle DF-PROM significantly } \\
\text { increased in the S-MWM group by } 53.5 \% \\
\text { after } 4 \text { weeks of study intervention. }\end{array}$ \\
\hline
\end{tabular}

(Continued) 
Table I (Continued).

\begin{tabular}{|c|c|c|c|c|}
\hline Authors & Participants & Intervention & $\begin{array}{l}\text { Outcome } \\
\text { Measures }\end{array}$ & Results \\
\hline $\begin{array}{l}\text { Donghwan } \\
\text { Park et al } \\
(2018)^{16}\end{array}$ & $\begin{array}{l}28 \text { chronic stroke } \\
\text { patients: } \\
E G(n=14), C G \\
(n=14) \\
\text { Mean age (years): } \\
E G=64.1(9.7) \\
C G=57.6(9) \\
\text { Duration since } \\
\text { stroke(months): } \\
E G=11.28(3.6) \\
C G=9.1(1.9)\end{array}$ & $\begin{array}{l}\text { EG=S-MWMI } 0^{\circ} \text { inclined board training } \\
\text { sessions were performed } 3 \text { times per week } \\
\text { for } 4 \text { weeks } \\
\text { CG=S-MWMI0 performed } 3 \text { times per week } \\
\text { for } 4 \text { weeks. } \\
\text { Both arms attended standard rehabilitation } \\
\text { therapy (PROM \&AROM exercise, weight } \\
\text { bearing exercise, and walking) for } 30 \text { minutes } \\
\text { per session. }\end{array}$ & $\begin{array}{l}\text { DF- PROM } \\
\text { SBA } \\
\text { BBS } \\
\text { K-MBI } \\
\text { GAITRite }\end{array}$ & $\begin{array}{l}\text { Relative to the S-MWM group, S-MWM } 10^{\circ} \\
\text { inclined board group demonstrated } \\
\text { significantly improved ankle dorsiflexion } \\
\text { passive range of motion, static balance ability, } \\
\text { gait speed, cadence, and affected-sidestep } \\
\text { length. }\end{array}$ \\
\hline $\begin{array}{l}\text { Chang-Man } \\
\text { An and } \\
\text { Jong-Im } \\
\text { Won } \\
(2016)^{25}\end{array}$ & $\begin{array}{l}30 \text { chronic stroke } \\
\text { patients: } \\
E G I(n=I 2), E G 2 \\
(n=8), C G \\
(n=I 0) \\
\text { Mean age (years) } \\
E G I=48.3(I I .5), \\
E G 2=50.5(9.9), \\
C G=47.4(I 0.7) \\
\text { Duration since } \\
\text { stroke(months): } \\
E G I=60(36.6) \\
E G 2=50.6(34.6) \\
C G=62.7(4 I)\end{array}$ & $\begin{array}{l}E G I=M W M \text { plus CPT } 3 \text { times a week for } 5 \\
\text { weeks } \\
E G 2=W B E \text { plus CPT } 3 \text { times a week for } 5 \\
\text { weeks } \\
\text { CG = CPT } 3 \text { times a week for } 5 \text { weeks }\end{array}$ & $\begin{array}{l}\text { DF- PROM } \\
\text { K-MBI } \\
\text { GAITRite }\end{array}$ & $\begin{array}{l}\text { Results indicated that knee extensor peak } \\
\text { torque improved significantly in MWM and } \\
\text { WBE groups, but, only the MWM group } \\
\text { revealed significant improvement in passive } \\
\text { and active ankle range of motion and gait } \\
\text { velocity, among the three groups }\end{array}$ \\
\hline $\begin{array}{l}\text { Sang-Lim } \\
\text { Kim and } \\
\text { Byoung-Hee } \\
\text { Lee } \\
(2016)^{23}\end{array}$ & $\begin{array}{l}24 \text { chronic stroke } \\
\text { patients: } \\
E G(n=12), C G \\
(n=12) \\
\text { Mean age (years): } \\
E G=41.58, \\
C G=53.0 \\
\text { Duration since } \\
\text { stroke(months): } \\
E G=8.87 \\
C G=10.46\end{array}$ & $\begin{array}{l}\text { EG = Grade III, MWM followed } 5 \text { sets of } 10 \\
\text { glides a day, } 5 \text { times a week for a month. } \\
\text { CG= placebo MWM followed for } 5 \text { sets of } 10 \\
\text { lunges a day, } 5 \text { times a week for } 4 \text { weeks. } \\
\text { All study participants received CPT for } 30 \\
\text { minutes per day, } 5 \text { days per week over } \\
\text { a 4-week period. }\end{array}$ & GAITRite & $\begin{array}{l}\text { MWM group indicated higher improvements } \\
\text { in velocity which increased from } 41.35 \mathrm{~cm} / \mathrm{s} \\
\text { before training to } 51.72 \mathrm{~cm} / \mathrm{s} \text { after training } \\
(\mathrm{p}<0.00 \mathrm{I}) \text {; cadence, step length, stride } \\
\text { length, and single-support time of the } \\
\text { affected side; and step length and stride } \\
\text { length of the non-affected side }(\mathrm{p}<0.05) \text {. The } \\
\text { MWM group showed significantly higher } \\
\text { improvements than the CG in terms of } \\
\text { velocity, cadence, and single-support time of } \\
\text { the affected side }(p<0.05)\end{array}$ \\
\hline
\end{tabular}

Abbreviations: EG, experimental group; CG, control group; BBS, Berg balance scale; DF-PROM, dorsiflexion passive range of motion; K-MBI, Korean version of the Modified Barthel Index; SBA, static balance ability; S-MWM, self-mobilization with movement; S-MWMI0', self-mobilization with movement with $10^{\circ}$ incline board; MAS, Modified Ashworth scale; WBLT, weight bearing lunge test; TUGT, timed up and go test; DGI, dynamic gait index; WBE, weight bearing exercise; MWM, mobilization with movement; PROM, passive range of movement; CMS, calf muscle stretching; SMS, static muscle stretching.

therapy on ROM, balance, and gait functions in chronic stroke survivors. The majority of the included studies with moderate to high methodological quality indicated that MWMs are effective in improving ROM, balance, and gait function in chronic stroke survivors. The general effects of MWMs on chronic stroke subjects turned into evaluated for specific period of intervention. The effects of MWMs on balance and gait function were evaluated in seven studies. Out of them, six studies confirmed that using MWMs could improve balance ability and all of them confirmed that MWMs had important effect on gait function compared to the control groups. Out of the included studies; five trials with individuals investigated the effectiveness of MWMs on ankle ROM. All of them 
Table 2 Methodological Quality of Included RCTs

\begin{tabular}{|c|c|c|c|c|c|c|c|}
\hline PEDro Items & $\begin{array}{l}\text { Chang-Man } \\
\text { An, and, Jong- } \\
\text { Im Won } \\
(2016)^{25}\end{array}$ & $\begin{array}{l}\text { Sang-Lim Kim, } \\
\text { and Byoung- } \\
\text { Hee Lee } \\
(2016)^{23}\end{array}$ & $\begin{array}{l}\text { Chang- } \\
\text { Man, and } \\
\text { Shin-Ok Jo } \\
(20 \quad 17)^{24}\end{array}$ & $\begin{array}{l}\text { Donghwan } \\
\text { Park et al } \\
(2018)^{16}\end{array}$ & $\begin{array}{l}\text { Sang-Lim Kim, } \\
\text { and Byoung-Hee } \\
\text { Lee }(2018)^{15}\end{array}$ & $\begin{array}{l}\text { Park } \\
\text { et al } \\
(2019)^{26}\end{array}$ & $\begin{array}{l}\text { Park } \\
\text { et al } \\
(2020)^{27}\end{array}$ \\
\hline Eligibility & Yes & Yes & Yes & Yes & Yes & Yes & No \\
\hline Random allocation & Yes & Yes & Yes & Yes & Yes & Yes & Yes \\
\hline Concealed allocation & No & No & Yes & No & No & No & No \\
\hline Baseline comparability & Yes & Yes & Yes & Yes & Yes & Yes & Yes \\
\hline Blinded participants & No & No & No & No & No & No & No \\
\hline Blinded therapists & No & No & No & No & No & No & No \\
\hline Adequate follow-up & Yes & Yes & Yes & Yes & Yes & Yes & Yes \\
\hline Blinded assessors & No & Yes & No & Yes & Yes & Yes & Yes \\
\hline Intention to treat analysis & No & Yes & No & No & Yes & Yes & Yes \\
\hline $\begin{array}{l}\text { Between-group } \\
\text { comparisons }\end{array}$ & Yes & Yes & Yes & Yes & Yes & Yes & Yes \\
\hline $\begin{array}{l}\text { Point estimates and } \\
\text { variability }\end{array}$ & Yes & No & Yes & Yes & Yes & Yes & Yes \\
\hline Total score & $5 / 10$ & $6 / 10$ & $6 / 10$ & $6 / 10$ & $7 / 10$ & $7 / 10$ & $7 / 10$ \\
\hline
\end{tabular}

demonstrated that ankle range of motion of chronic stroke survivors was substantially improved in MWMs groups compared to control groups. Kim et $\mathrm{al}^{23}$ found that MWM improved gait spatial parameters (velocity, cadence, stride length, single-support time, and step length of the affected side) when compared to control groups. The MWM group improved dramatically in single-support time of the affected side, increasing from $20.08 \%$ gait cycle before training to $23.33 \%$ gait cycle after training. Likewise, a study performed by Park ${ }^{16}$ mentioned that self-ankle MWM with a $10^{\circ}$ inclined board $\left(\mathrm{MWM} 10^{\circ}\right)$ combined with $\mathrm{CPT}$ had improved motor function in the individuals with chronic stroke. The self-ankle MWM with a $10^{\circ}$ inclined board group had significantly improved ankle dorsiflexion passive ROM, static balance strength, gait speed, cadence, and affected-side step duration after 4 weeks of interventions. Despite this, the post-treatment K-MBI and BBS scores did not vary significantly between the trial groups. Nonetheless, in both arms, the K-MBI and BBS scores increased significantly after treatment as compared to the baseline scores. Ankle DF-PROM was significantly increased by $54.9 \%$ and $\mathrm{SBA}$ by $53.1 \%$ in the $\mathrm{S}-\mathrm{MWM} 10^{\circ}$ groups relative to the S-MWM groups. In addition, after treatment, gait speed and cadence increased significantly by $42.8 \%$, and $24.0 \%$ in the $\mathrm{S}-\mathrm{MWM} 10^{\circ}$ groups respectively compared to the control groups. Similarly, the post-treatment step length on the affected side was increased by $19.4 \%$ in the S-MWM10 groups compared to the control groups.

Furthermore, the study conducted by Park et $\mathrm{al}^{26}$ demonstrated that balance ability and gait function in the MWM groups improved dramatically as compared to the SMS group; SBA and BBS ratings increased dramatically in the MWM group compared to the SMS group following therapy, by $227.8 \%$ and $266.7 \%$, respectively. After the 4-week intervention, ankle DF-PROM in the MWM group increased by $43.5 \%$ compared to the SMS group. Nonetheless, after therapy, ankle DF-PROM did not vary significantly between groups. This was comparable with two previous studies performed by Kim et al and MarronGomez. ${ }^{15,28}$ It may be due to an anterior posterior glide portion of WB-MWM, which decreases talar positional fault and restores posterior talar glide and ankle dorsiflexion. $^{13,29}$ Moreover, posterior talar glide is assumed to be an accessory motion for ankle dorsiflexion. $^{29}$ Thus, restoring of its motion leads to improved ankle dorsiflexion ROM. Similarly, An and Jo discovered that joint mobilization improved ankle strength, mobility, and weight bearing capacity test results in chronic stroke patients after 5 weeks as compared to control groups. ${ }^{24}$ The possible explanation may be that joint movement stimulates mechanoreceptor activation when stretching occurs in the capsule and ankle ligaments. It boosts their sensory activity by stimulating gamma motor neurons with tissue tension, Golgi tendon organs, 
and other proprioceptors, to help maintain balance. ${ }^{30,31}$ Yoon et $\mathrm{al}^{32}$ also performed weight bearing dependent joint mobilization and improved ankle joint ROM and heel off time, demonstrating the efficacy of ankle WBMWM. Kang et al, ${ }^{33}$ performed weight-bearing joint mobilization and recorded improvements in ankle joint ROM, heel off time, and dorsiflexion ROM prior to heel off during the stance phase.

According to the Park et al study, cadence in the MWM group improved by $207.6 \%$ after treatment compared to the SMS group. These findings are consistent with those of a previous study conducted by Johanson et al. ${ }^{34}$ Furthermore, Park et $\mathrm{al}^{27}$ concluded that ankle DFPROM, gait speed, cadence, and stride length on the affected side were substantially higher in the S-MWM group compared to the CMS group. This study found a substantial increase in ankle DFPROM, gait speed, cadence, and gait length on the affected side in the S-MWM group compared to the CMS group. After 4 weeks of study intervention, ankle DF-PROM in the S-MWM group increased by 53.5\% compared to the CMS group. These findings are in line with previous research by Kluding and Santos, and An and Jo. ${ }^{5,24}$ Following study intervention, the reduction in fall risk was significantly increased by $47.5 \%$ in the S-MWM group compared to the CMS group. Such findings are consistent with previous research. ${ }^{35,36}$

An and Jo discovered that the DF-PROM was significantly higher in the MWM group (mean changes, $6.67^{\circ}$ ) than in the control group (mean changes, $0.75^{\circ}$ ). Similarly, plantar flexor strength increased dramatically in the MWM group relative to control groups. This study found that talocrural MWM combined with conventional therapy is more beneficial for ankle kinetics and weightbearing capacity than conventional therapy alone in patients with chronic stroke who have reduced ankle range of motion. ${ }^{24}$ In addition, a study conducted by Kim and Lee ${ }^{15}$ reported that, in chronic stroke survivors, WBMWM enhanced the ankle range of motion, balance and gait compared to the control groups. It may be attributed to joint mobilization, which enhances the flexibility and extensibility of non-contractile tissues surrounding the talocrural joint. ${ }^{31}$ This improves more ankle joint movements in chronic stroke survivors. The study performed by Vicenzino et al also confirmed it. ${ }^{13}$ Likewise, a study performed by An and Won (2016) ${ }^{25}$ showed there was a significant improvement in ankle ROM (PROM and AROM) and gait velocity in the MWM category as compared with weight bearing exercise. It may be MWM mediated regeneration of accessory movement in the joints following a tibia forward gliding, accompanied by a transfer in the COM, resulting in improved joint ROMs.

Taken together; one study's findings may show that MWM had no impact on balance and gait function. Nonetheless, a more common explanation given the findings of six studies, indicated that MWMs had a substantial benefit in ankle ROM, balance and gait function in chronic stroke survivors compared to control groups.

\section{Limitations}

This review had the following limitations. This review included only English language articles. Thus, there might have been a possibility of missing articles published in non-English language. Due to heterogeneity of interventions, performing a meta-analysis was not possible.

\section{Clinical Implication}

This review demonstrated that MWMs exerted beneficial effects on ankle ROM, balance, and gait function for chronic stroke survivors. This finding may facilitate the decision making of clinicians regarding alternatives to the conventional management of ankle joint stiffness in chronic stroke subjects to determine the optimal treatment strategy.

\section{Conclusion}

Ankle joint mobilization with movement therapy could improve ankle ROM, balance, and gait spatial parameters in chronic stroke survivors. Large-scale RCTs in the future are warranted in subgroups of chronic stroke subjects.

\section{Ethical Approval}

Ethical approval or affected person consent was not needed.

\section{Author Contributions}

All authors made a significant contribution to the work reported, whether that is in the conception, study design, execution, acquisition of data, analysis and interpretation, or in all these areas; took part in drafting, revising or critically reviewing the article; gave final approval of the version to be published; have agreed on the journal to which the article has been submitted; and agree to be accountable for all aspects of the work. 


\section{Funding}

There were no supplied monetary help to conduct this review.

\section{Disclosure}

The authors report no conflicts of interest for this work.

\section{References}

1. O'dwyer N, Ada L, Neilson P. Spasticity and muscle contracture following stroke. Brain. 1996;119(5):1737-1749. doi:10.1093/brain/ 119.5.1737

2. Watkins C, Leathley MJ, Gregson JM, et al. Prevalence of spasticity post stroke. Clin Rehabil. 2002;16(5):515-522. doi:10.1191/026921 $5502 \mathrm{cr} 512 \mathrm{oa}$

3. Chung SG, van Rey E, Bai Z, et al. Biomechanic changes in passive properties of hemiplegic ankles with spastic hypertonia. Arch Phys Med Rehabil. 2004;85(10):1638-1646. doi:10.1016/j.apmr.2003. 11.041

4. Thilmann A, Fellows S, Ross H. Biomechanical changes at the ankle joint after stroke. J Neurol Neurosurg Psychiatry. 1991;54 (2):134-139. doi:10.1136/jnnp.54.2.134

5. Kluding PM, Santos M. Effects of ankle joint mobilizations in adults poststroke: a pilot study. Arch Phys Med Rehabil. 2008;89 (3):449-456. doi:10.1016/j.apmr.2007.12.005

6. Lin P-Y, Yang Y-R, Cheng S-J, et al. The relation between ankle impairments and gait velocity and symmetry in people with stroke. Arch Phys Med Rehabil. 2006;87(4):562-568. doi:10.1016/j. apmr.2005.12.042

7. Sommerfeld DK, Eek EU-B, Svensson A-K, et al. Spasticity after stroke: its occurrence and association with motor impairments and activity limitations. Stroke. 2004;35(1):134-139. doi:10.1161/01. STR.0000105386.05173.5E

8. Nakayama Y, Iijima S, Kakuda W, et al. Effect of home-based training using a slant board with dorsiflexed ankles on walking function in post-stroke hemiparetic patients. $J$ Phys Ther Sci. 2016;28(8):2353-2357. doi:10.1589/jpts.28.2353

9. Kaltenborn FM. Manual mobilization of the joints; The Kaltenborn method of joint examination and treatment. Extremities. 1999;21-28.

10. Hwang D-Y, Lee H-J, Lee G-C, et al. Treadmill training with tilt sensor functional electrical stimulation for improving balance, gait, and muscle architecture of tibialis anterior of survivors with chronic stroke: a randomized controlled trial. Technol Health Care. 2015;23 (4):443-452. doi:10.3233/THC-150903

11. Park Y-H, Kim Y-M, Lee B-H. An ankle proprioceptive control program improves balance, gait ability of chronic stroke patients. J Phys Ther Sci. 2013;25(10):1321-1324. doi:10.1589/jpts.25.1321

12. Exelby L. The mulligan concept: its application in the management of spinal conditions. Manual Ther. 2002;7(2):64-70. doi:10.1054/ math.2001.0435

13. Vicenzino B, Branjerdporn M, Teys $\mathrm{P}$, et al. Initial changes in posterior talar glide and dorsiflexion of the ankle after mobilization with movement in individuals with recurrent ankle sprain. J Orthopaedic Sports Phys Ther. 2006;36(7):464-471. doi:10.25 19 /jospt.2006.2265

14. Sahrmann S. Movement System Impairment Syndromes of the Extremities, Cervical and Thoracic Spines-e-Book. Elsevier Health Sciences; 2010.

15. Kim S-L, Lee B-H. The effects of posterior talar glide and dorsiflexion of the ankle plus mobilization with movement on balance and gait function in patient with chronic stroke: a randomized controlled trial. J Neurosci Rural Pract. 2018;9(1):61. doi:10.4103/jnrp.jnrp_382_17
16. Park D, Lee J-H, Kang T-W, et al. Effects of a 4-week self-ankle mobilization with movement intervention on ankle passive range of motion, balance, gait, and activities of daily living in patients with chronic stroke: a Randomized Controlled Study. J Stroke Cerebrovasc Dis. 2018;27(12):3451-3459. doi:10.1016/j. jstrokecerebrovasdis.2018.08.010

17. Moher D, Shamseer L, Clarke M, et al. Preferred reporting items for systematic review and meta-analysis protocols (PRISMA-P) 2015 statement. Syst Rev. 2015;4(1):1. doi:10.1186/2046-4053-4-1

18. Richardson WS, Richardson WS, Wilson MC, et al. The well-built clinical question: a key to evidence-based decisions. ACP J Club. 1995;123(3):A12-3. doi:10.7326/ACPJC-1995-123-3-A12

19. Villanueva EV, Burrows EA, Fennessy PA, et al. Improving question formulation for use in evidence appraisal in a tertiary care setting: a randomised controlled trial [ISRCTN66375463]. BMC Med Inf Dec Making. 2001;1(1):4. doi:10.1186/1472-6947-1-4

20. Snowball R. Using the clinical question to teach search strategy: fostering transferable conceptual skills in user education by active learning. Health Libraries Rev. 1997;14(3):167-172. doi:10.1046/ j.1365-2532.1997.1430133.x-i1

21. de Morton NA. The PEDro scale is a valid measure of the methodological quality of clinical trials: a demographic study. Aust $J$ Physiother. 2009;55(2):129-133. doi:10.1016/S0004-9514(09) 70043-1

22. Maher CG, Sherrington C, Herbert RD, et al. Reliability of the PEDro scale for rating quality of randomized controlled trials. Phys Ther. 2003;83(8):713-721. doi:10.1093/ptj/83.8.713

23. Kim S-L, Lee B-H. Effect of mulligan's mobilization with movement technique on gait function in stroke patients. $J$ Phys Ther Sci. 2016;28(8):2326-2329. doi:10.1589/jpts.28.2326

24. An C-M, Jo S-O. Effects of talocrural mobilization with movement on ankle strength, mobility, and weight-bearing ability in hemiplegic patients with chronic stroke: a randomized controlled trial. $J$ Stroke Cerebrovasc Dis. 2017;26(1):169-176. doi:10.1016/j.jstrokecerebrovasdis.2016.09. 005

25. An C-M, Won J-I. Effects of ankle joint mobilization with movement and weight-bearing exercise on knee strength, ankle range of motion, and gait velocity in patients with stroke: a pilot study. $J$ Phys Ther Sci. 2016;28(2):689-694. doi:10.1589/jpts.28.689

26. Park D, Lee J-H, Kang T-W, et al. Four-week training involving ankle mobilization with movement versus static muscle stretching in patients with chronic stroke: a randomized controlled trial. Topics Stroke Rehabil. 2019;26(2):81-86. doi:10.1080/10749357.2018.15 50614

27. Park D, Cynn H-S, Yi C, et al. Four-week training involving self-ankle mobilization with movement versus calf muscle stretching in patients with chronic stroke: a randomized controlled study. Topics Stroke Rehabil. 2020;27(4):296-304. doi:10.1080/10749357.2019. 1690831

28. Marrón-Gómez D, Rodríguez-Fernández ÁL, Martín-Urrialde JA. The effect of two mobilization techniques on dorsiflexion in people with chronic ankle instability. Phys Ther Sport. 2015;16(1):10-15. doi:10.1016/j.ptsp.2014.02.001

29. Kisner C, Colby LA. Therapeutic Exercise Foundations and Techniques Foundations. Philadelphia: FA Davis Company; 2012.

30. Hiller CE, Refshauge KM, Bundy AC, et al. The Cumberland ankle instability tool: a report of validity and reliability testing. Arch Phys Med Rehabil. 2006;87(9):1235-1241. doi:10.1016/j.apmr.2006.05.022

31. Levangie PK, Norkin CC. Joint Structure and Function: A Comprehensive Analysis. 3rd ed. Philadelphia, FA: Davis Company; 2000.

32. Yoon J-Y, Hwang Y-I, An D-H, et al. Changes in kinetic, kinematic, and temporal parameters of walking in people with limited ankle dorsiflexion: pre-post application of modified mobilization with movement using talus glide taping. J Manipul Physiol Ther. 2014;37(5):320-325. doi:10.1016/j.jmpt.2014.01.007 
33. Kang M-H, Kim J-W, Choung S-D, et al. Immediate effect of walking with talus-stabilizing taping on ankle kinematics in subjects with limited ankle dorsiflexion. Phys Ther Sport. 2014;15(3):156-161. doi:10.1016/j.ptsp.2013.09.001

34. Johanson MA, Cuda BJ, Koontz JE, et al. Effect of stretching on ankle and knee angles and gastrocnemius activity during the stance phase of gait. J Sport Rehabil. 2009;18(4):521-534. doi:10.1123/ jsr.18.4.521
35. Marigold DS, Eng JJ, Dawson AS, et al. Exercise leads to faster postural reflexes, improved balance and mobility, and fewer falls in older persons with chronic stroke. J Am Geriatrics Soc. 2005;53 (3):416-423. doi: $10.1111 / \mathrm{j} .1532-5415.2005 .53158 . x$

36. Menz HB, Morris ME, Lord SR. Foot and ankle risk factors for falls in older people: a prospective study. J Gerontol Ser A. 2006;61 (8):866-870. doi:10.1093/gerona/61.8.866

\section{Publish your work in this journal}

Degenerative Neurological and Neuromuscular Disease is an international, peer-reviewed, open access journal focusing on research into degenerative neurological and neuromuscular disease, identification of therapeutic targets and the optimal use of preventative and integrated treatment interventions to achieve improved outcomes, enhanced survival and quality of life for the patient. The manuscript management system is completely online and includes a very quick and fair peer-review system. Visit http://www.dovepress.com/ testimonials.php to read real quotes from published authors. 